\title{
EDUCAÇÃO E DIREITOS HUMANOS NA ERA DIGITAL: A ANÁLISE DO OBJETO EDUCACIONAL “JOGO DO ORÇAMENTO”
}

Cristiéle Picolo Visoná, Letícia Rodrigues Biassoti, Luis Henrique Ramos Alves, Myllena Silva, Sarah Carolina Colorado Borges, Jéssica Fernanda Alves Cavalcante, Raquel Rosan Christino Gitahy

Universidade do Oeste Paulista - UNOESTE, Presidente Prudente SP.

\section{RESUMO}

O presente trabalho teve como objetivo analisar o objeto educacional "jogo do orçamento", obtido por meio de um levantamento de recursos de tecnologia digital de informação e comunicação que estivessem disponíveis gratuitamente em repositórios que instiguem a reflexão a respeito do tema Educação em Direitos Humanos. A obtenção de tal objeto foi no banco internacional de objetos educacionais. A análise do recurso foi feita a partir de algumas diretrizes dos Direitos Humanos, inspirados na resolução no 1, que estabelece Diretrizes Nacionais para a Educação em Direitos Humanos. Observou-se que o objeto educacional "Jogo do orçamento" evidencia as diretrizes constantes na resolução no 1, podendo ser usado como ferramenta de reflexão dos Direitos Humanos.

Palavras chaves: Direitos humanos; Educação; Tecnologia digital de informação e comunicação; orçamento; objeto educacional.

\section{EDUCATION AND HUMAN RIGHTS IN THE DIGITAL ERA: THE ANALYSIS OF THE EDUCATIONAL OBJECT "GAME OF THE BUDGET"}

\begin{abstract}
This paper has as objective to analyze or educational object "budget game", obtained by means of a digital resources of information technology and communication that is available free of charge in archives that instigate the reflection about education and Human Right. A obtaining of such an object is not an international bank of educational objects. A foreseeable resource analysis from some directions two Human Rights, inspired by Resolution Number 1, which establishes National Directorates for Education in Human Rights. It was observed that the educational object "Game of the budget" shows the guidelines contained in resolution no. 1, and can be used as a tool for reflection on human rights.
\end{abstract}

Keywords: Human right; Education; Digital technology of information and communication; budget; educational object. 


\title{
INTRODUÇÃO E JUSTIFICATIVA
}

A sociedade digital incentiva o impulso às criações tecnológicas. Simão Neto (2002) descreve o uso da tecnologia na Educação como ondas, entre as quais destaca:

\author{
Primeira onda: software Logo e programação \\ Segunda onda: informática básica \\ Terceira onda: Software educativo \\ Quarta onda: internet \\ Quinta onda: aprendizagem colaborativa \\ Sexta onda: o que será?. (SIMÃO NETO, 2002, p.71).
}

Segundo Brito e Purificação (2006), o primeiro movimento que teve grande repercussão no meio acadêmico, promovendo a produção de diversas pesquisas e o desenvolvimento de projetos em muitas escolas, foi o programa LOGO. Mesmo com a comprovação da potencialidade desse software na aprendizagem, na criatividade e na autonomia dos alunos, sua implantação no contexto escolar não ocorreu como se previa.

Concomitantemente a esse movimento, a formação dos professores para a utilização da informática no Brasil vem acontecendo, buscando a melhor forma de empregar os recursos proporcionados por ela e tendo a percepção sobre quais mudanças podem ocorrer na escola, sobretudo no ensino-aprendizagem. Porque não utilizar essas tecnologias no processo de ensino?

Pensando nos temas relevantes ao processo de ensino, o presente trabalho destaca a Educação para os Direitos Humanos.

A união entre a Educação e os Direitos Humanos já existe de maneira retraída na tentativa de ganhar cada vez mais espaço nas pesquisas, nas discussões e na prática, porém para melhor compreensão apontamentos devem ser feitos. De acordo com Gorczevski e Martín (2015), existem diferenças relevantes entre os conceitos Educação para os Direitos Humanos e Educação em Direitos Humanos, estes causam inúmeros conflitos doutrinários, de modo a necessitar de uma análise individualizada de cada um.

O primeiro, refere-se a propagação desses direitos, a compreensão de quais são eles, o que pretendem, porque existem, em que se fundamentam, com o objetivo de por meio desses questionamentos o indivíduo conheça, exerça seus direitos e respeite os dos outros. $O$ segundo, relaciona-se a Pedagogia, a forma utilizada de transmitir o conhecimento sobre esses direitos, como e quais os procedimentos serão adotados. Todavia, o educador deve ser o modelo a ser seguido, seu discurso e suas atitudes devem estar em consonância. "Toda educação para os direitos humanos deve acontecer em uma educação em direitos humanos". (GORCZESKI; MARTíN, 2015, p. 35).

Vivencia-se atualmente uma realidade educacional que deve considerar também a era digital:

\begin{abstract}
Nas últimas décadas, assistimos à dotação das escolas de linhas de acesso à Internet com velocidades cada vez mais rápidas. A par da rapidez do acesso, temos assistido à introdução de novos meios de acesso. Do acesso fixo, cabeado, através de computadores de secretária, as escolas possuem hoje redes sem fios (Wi-Fi) que dão acesso a computadores portáteis (laptop), tablets e smartphones. Tal foi igualmente acompanhado pela substituição dos quadros de ardósia por quadros interativos, vídeos projetores (datashow), apontadores laser e canetas digitais. (ABRUSIO, 2015, p. 50)
\end{abstract}

A tecnologia permeia desde os mais jovens aos mais velhos. Desse modo, a construção de valores educacionais de Direitos Humanos em uma cidadania digital deve ser aprimorada para estar inserida no cotidiano dos nativos digitais, com o uso de jogos, redes sociais, desde o Facebook com vídeos, até o Instagram com postagens informativas objetivas, canais no Youtube, com a dinamicidade requerida pelo jovem em favor de uma causa social. Em análise desses meios tecnológicos com base nos princípios norteadores dos Direitos Humanos, trazidos pelo Conselho 
Nacional de Educação em sua Resolução no 1, que estabelece Diretrizes Nacionais para a Educação em Direitos Humanos, sendo eles:

(I)- dignidade humana; (II) - igualdade de direitos; (III) - reconhecimento e valorização das diferenças e das diversidades; (IV) - laicidade do Estado; (V) - democracia na educação; (VI) - transversalidade, vivência e globalidade; e (VII) - sustentabilidade socioambiental. (GORCZESKI; MARTíN, 2015, p. 70)

Numa sociedade que a desigualdade é cada vez mais acentuada principalmente em decorrência de fatores econômicos e de distribuição de renda, é fundamental que se tenha uma educação sólida, bem aplicada para suprir tamanha discrepância entre os cidadãos, acima de tudo deve ser eficaz, que se utilize dos meios inovadores gerados pela tecnologia para realizar uma conscientização dos direitos e deveres próprios e alheios, desde a mais tenra idade, a fim de constituir indivíduos críticos, para que se alcance uma luta justa pelas garantias que um Estado Democrático prevê.

O objetivo da presente pesquisa foi analisar o objeto educacional "jogo do orçamento", obtido por meio de um levantamento de recursos de tecnologia digital de informação e comunicação que estivessem disponíveis gratuitamente em repositórios que instiguem a reflexão a respeito do tema Educação em Direitos Humanos

\section{METODOLOGIA}

A pesquisa foi qualitativa e o contexto para a coleta de dados ocorreu no banco internacional de objetos educacionais. O banco internacional de objetos educacionais encontra-se no endereço http://objetoseducacionais2.mec.gov.br/ e possui objetos educacionais de acesso público, em vários formatos e para todos os níveis de ensino. Os tipos de objetos disponíveis neste repositório são: animação/simulação; imagem; mapa; experimento prático; software educacional; hipertexto e vídeo

Figura 1. Tela do banco internacional de objetos educacionais

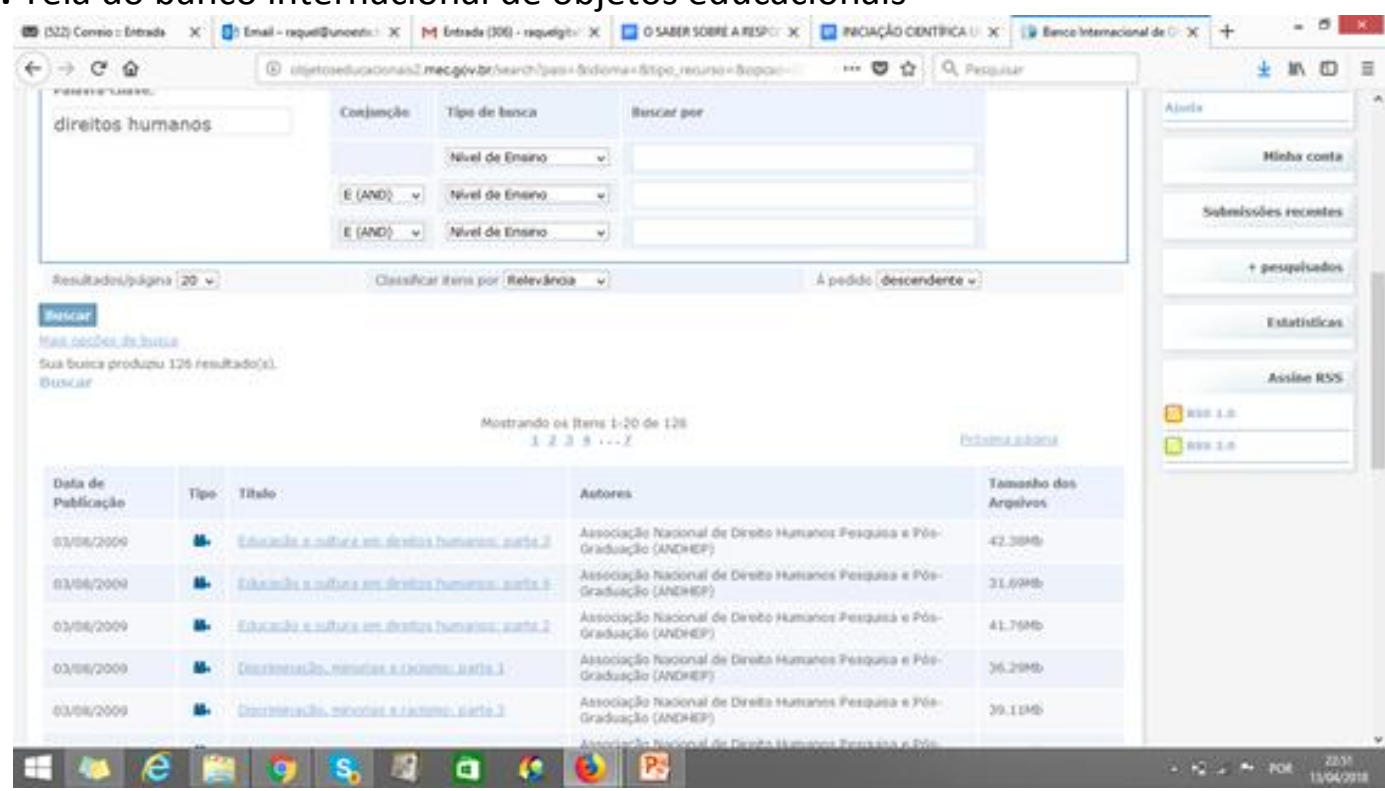

Fonte: http://objetoseducacionais2.mec.gov.br/

Como palavras chaves utilizamos "Direitos Humanos", na modalidade de objeto educacional "animações e simulações". Salientamos que esta pesquisa não necessitou da tramitação no comitê de ética pois os objetos educacionais, são de domínio público. 


\section{RESULTADOS} eletrônico

Dentre um dos resultados encontramos o "jogo do orçamento" disponível no endereço “http://imagem.camara.gov.br/internet/midias/plen/swf/Jogos/jogo do orcamento/jogo do orc amento.htm". O objetivo do jogo, segundo descrição no Banco internacional de objetos educacionais é "mostrar como se planeja e se executa as finanças públicas e quais os impactos de uma má administração para a sociedade", e a descrição do recurso é "esse jogo simula uma administração pública através do orçamento público que possibilita aos governantes o orçamento e a execução das finanças públicas. As Finanças Públicas abrangem a captação de recursos pelo Estado, sua gestão e seu gasto para atender às necessidades da coletividade e do próprio Estado". A figura 2 evidencia como é realizada a simulação.

Figura 2. Tela do objeto educacional Jogo do Orçamento

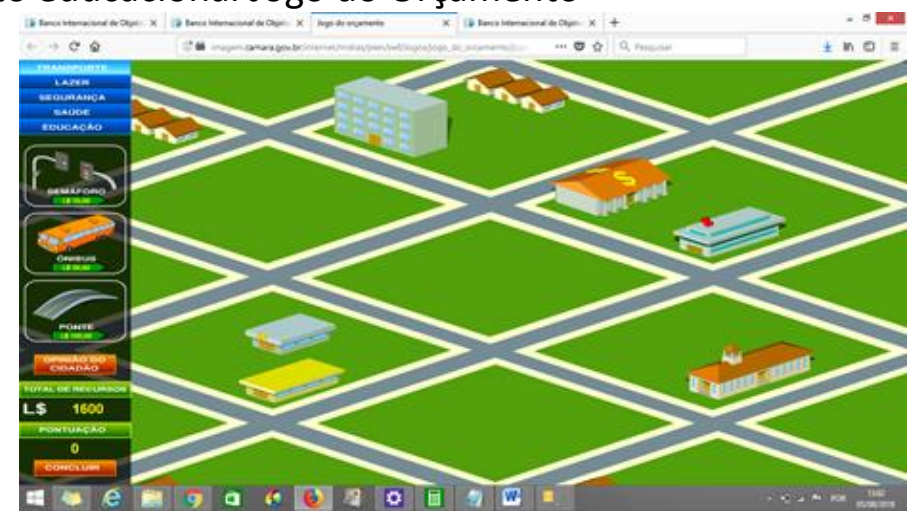

Fonte: http://imagem.camara.gov.br/internet/midias/plen/swf/Jogos/jogo_do_orcamento/jogo_do_orcamento.htm

\section{DISCUSSÃO}

O jogo apresentado abre a possibilidade de discussão sobre as áreas de investimento tendo em vista o bem estar de todos, cumprindo-se o artigo 3 da Constituição Federal, ou seja o bem estar de todos e o desenvolvimento nacional, uma vez que este busca mostrar que é necessário investimento que considera todas as áreas como Saúde, Educação, Lazer, Segurança e Transporte. O jogo gera um pensamento crítico, mostrando que quando há apenas investimentos em uma determinada área, não se realiza a questão dos Direitos Humanos em sua plenitude. Muitas vezes a forma de investimento dos governantes gera uma violação a direitos fundamentais da população, quando não se dá de forma equilibrada, a desigualdade aumenta. Para demonstrar tal pensamento, após alguns investimentos, o jogo gera uma reflexão a respeito das áreas que foram esquecidas e qual o impacto que isto pode gerar a sociedade, como pode ser evidenciado pela figura 03. 
Figura 3. Tela de reflexão sobre os investimentos realizados

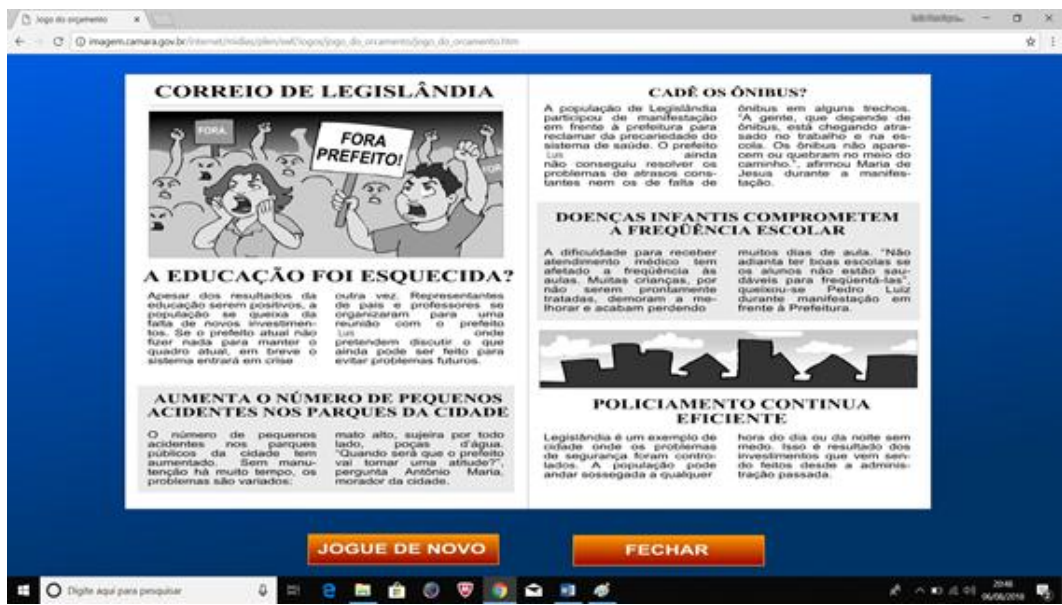

Fonte:http://imagem.camara.gov.br/internet/midias/plen/swf/Jogos/jogo_do_orcamento/jogo_do_orcamento.htm

Por outro lado quando há um pleno investimento, passa-se a ser possível um aumento da igualdade de direitos, pois todas as áreas funcionarão de forma integral, conforme evidencia a figura 4

Figura 4. Tela final após investimentos em todas as áreas

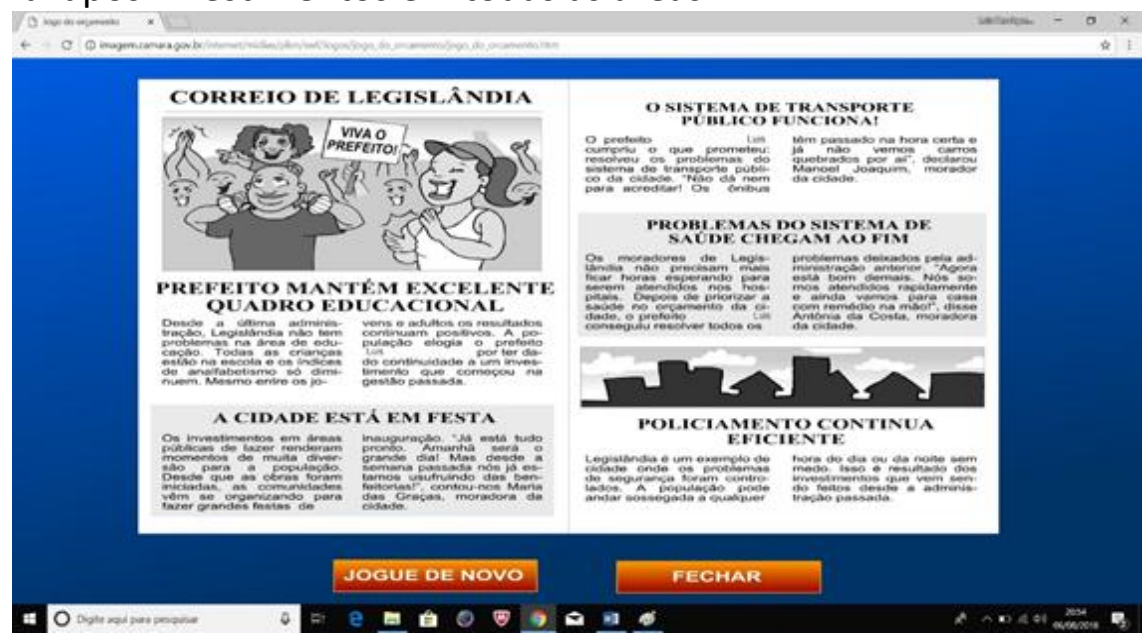

Fonte:http://imagem.camara.gov.br/internet/midias/plen/swf/Jogos/jogo_do_orcamento/jogo_do_orcamento.htm

O jogo também considera diversas opiniões, preferências e interesses. O jogo nos proporciona analisar o quão importante é reconhecer e valorizar as diversidades sociais, isto porque, uma gestão somente é justa e eficaz quando atende a todos.

O grande recurso trazido pelo jogo, consiste no fato de que, mesmo com diversos avanços da cidade em todas as áreas, a análise devolutiva feita pelos cidadãos contém a opinião pública, de modo que, nos possibilita notar todos os setores sociais e suas diferenças, inclusive aqueles que, por vezes, ficam esquecidos e desvalorizados. Consequentemente, quando reconhecemos os anseios dessas classes, estaremos mais propensos a atendê-las. Vejamos: 
Figura 5. Reflexão sobre um problema

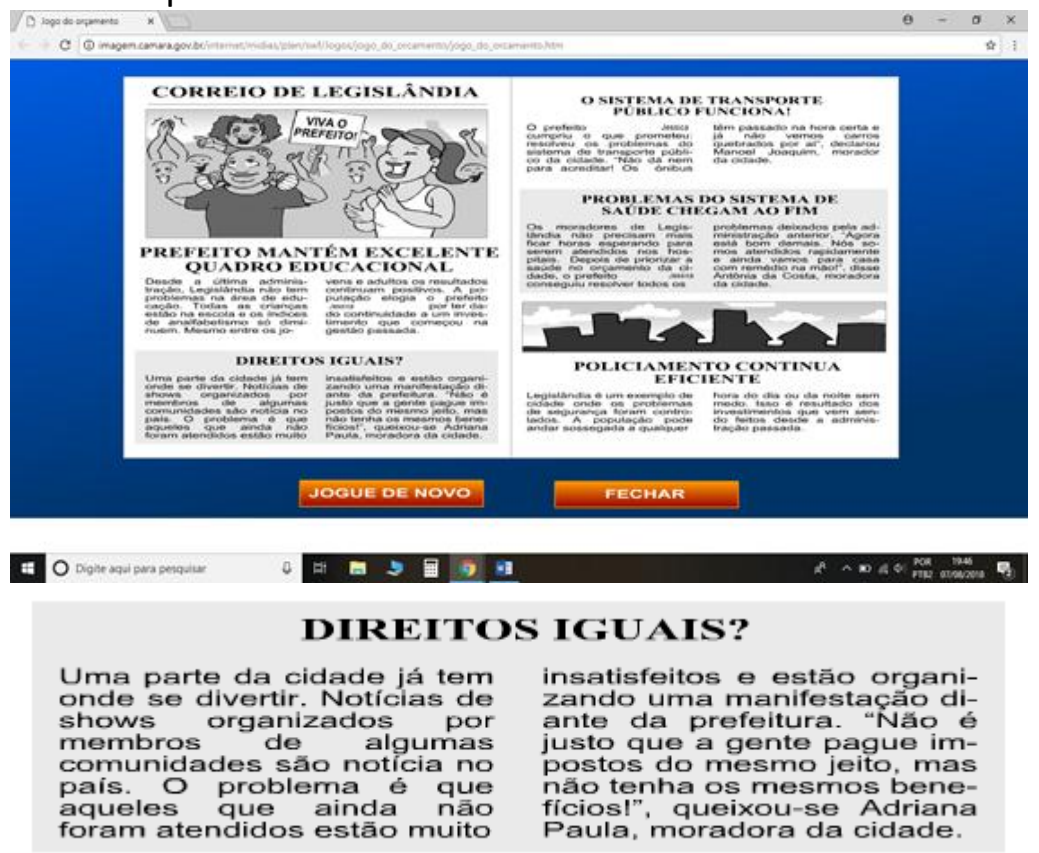

Fonte:http://imagem.camara.gov.br/internet/midias/plen/swf/Jogos/jogo_do_orcamento/jogo_do_orcamento.htm

Portanto, é possível notar que, ainda que se atenha aos anseios de um determinado público, é preciso que todos esses tenham seus direitos resguardados e tenham seu espaço preenchido na sociedade.

O jogo, finalmente, traz elementos de discussão quanto a sustentabilidade socioambiental. O tripé da sustentabilidade abrange: aspectos sociais (pessoas e suas condições de vida constatados no jogo como educação, saúde, etc), ambientais e econômicos, todos devem estar em consonância para que haja conscientização. (MAGALHÃES, 2018).

Apesar de ser um recurso digital fictício, por meio de outra simulação, nota-se que mesmo com a maioria das esferas atendidas positivamente, a população ainda não se demonstrou satisfeita quanto ao transporte, entretanto, é inexistente a demonstração de busca por outros meios alternativos de locomoção - bicicletas, caminhadas - o que reflete a falta de preocupação com aspectos ambientais, no caso, poluentes causados pelo transporte público. Logo, há a ausência da educação direcionada a questões ecológicas, assim como a inclusão de um pensamento crítico diante deste cenário. 
Figura 6. Reflexão sobre o transporte

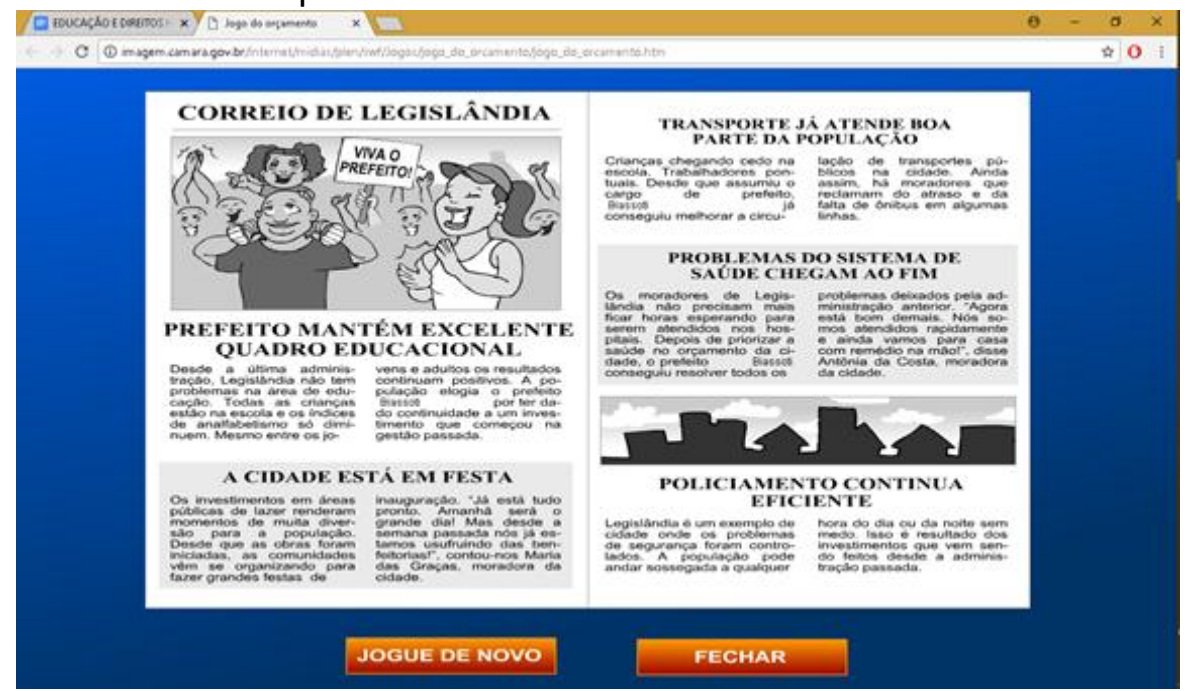

Fonte:http://imagem.camara.gov.br/internet/midias/plen/swf/Jogos/jogo_do_orcamento/jogo_do_orcamento.htm

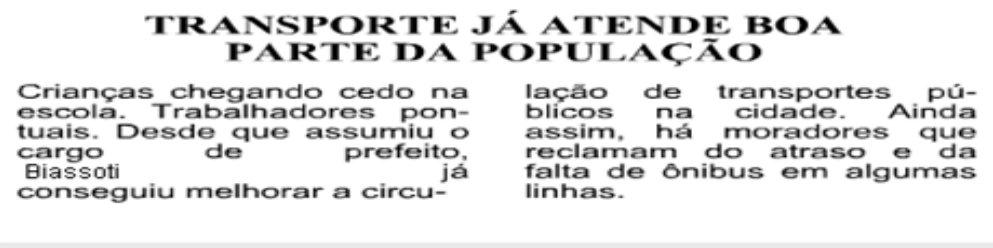

\section{CONCLUSÃO}

Conclui-se que a tecnologia digital de informação e comunicação, por meio de objetos educacionais pode auxiliar a discussão Educação e Direitos Humanos. O contexto do "jogo do orçamento" pode ser uma ferramenta a ser utilizada para a discussão a respeito das diferenças sociais, a importância da administração pública e sua influência na criação de melhores condições de inclusão, sustentabilidade, segurança e condição humana mais digna.

\section{REFERÊNCIAS}

ABRUSIO, J. (Coord.). Educação digital. São Paulo: Revista dos Tribunais, 2015.

BRITO, G. S.; PURIFICAÇÃO, I. Educação e novas tecnologias: um (re)pensar. 3. ed. Rev. atual. e ampl. Curitiba: IBPEX, 2006.

GORCZEVKI. C; MARTÍN, N. B. Educar para os direitos humanos: considerações, obstáculos, propostas. 1. ed. São Paulo: Atlas, 2015.
MAGALHÃES,
L.
Sustentabilidade.
Disponível
em:

<https://www.todamateria.com.br/sustentabilidade/ > Acesso em: 06 ago. 2018.

SIMÃO NETO, A. As cinco ondas da informática educacional. Revista Educação em Movimento, Curitiba, v.1, n.2, maio/ago. 2002. 